\title{
Reducing perceived stress through an orientation program for nursing students entering their first nursing course
}

\author{
Lisa Sparacino ** B. Suzy Diggle \\ Department of Nursing, New York Institute of Technology, New York, New York, United States
}

Received: February 14, 2017

DOI: $10.5430 /$ jnep.v7n9p54

\author{
Accepted: March 24, 2017 \\ Online Published: April 10, 2017 \\ URL: https://doi.org/10.5430/jnep.v7n9p54
}

\begin{abstract}
Background: The faculty of an introductory nursing course noted that students expressed, over several years, apprehension regarding expectations such as studying for exams and how to better organize their time. Nursing students are known to experience a greater amount of anxiety than non-nursing students. This anxiety interferes with their ability to be successful in their selected major.

Purpose and methods: The purpose of this study was to determine if an orientation program would reduce the perceived anxiety of students who have been admitted to their first nursing course, and of their families and significant others. Spielberger's State-Trait Anxiety Questionnaire was administered to measure changes in stress levels before and after exposure to an orientation program designed for incoming nursing students and their significant others.

Results and conclusions: The results indicated that the anxiety levels of the participants were significantly reduced after the orientation program. The results are important as a decrease in the anxiety levels of nursing students could be directly correlated to their success.
\end{abstract}

Key Words: Nursing students, Anxiety, Stress, Orientation program, Nursing education

\section{INTRODUCTION}

After teaching the introductory nursing course in a baccalaureate nursing program for several years, the authors noticed a pattern of anxiety demonstrated by the students. They continuously expressed apprehension regarding what was expected of them, for example, how to study for exams and how to better organize their time. ${ }^{[1]}$ It has been found that nursing students typically experience higher levels of anxiety than students in other areas of study regarding achieving success. Nursing faculty has a role in decreasing nursing students' anxiety. ${ }^{[1]}$ In our course, we spent a great deal of time during the first several classes trying to alleviate students' fears and anxiety. Despite these in-class efforts, the students continued to demonstrate a high level of apprehension through verbal expressions with their instructors. This anxiety was considered to be a significant problem among nursing students and a deterrent to success. ${ }^{[2]}$

Educators need to seek out ways to help students decrease their anxiety. ${ }^{[1]}$ Cognitive therapy has been shown to be a way to reduce stress and was directly related to decreased anxiety in nursing students. ${ }^{[3]}$ In this study it was hypothesized that developing an understanding of the demands of

\footnotetext{
*Correspondence: Lisa Sparacino; Email: 1sparaci@nyit.edu; Address: Department of Nursing, New York Institute of Technology, New York, New York, United States.
} 
the program, as well as providing a forum for students, their families and significant others to verbalize concerns and questions, would help lower the anxiety levels of nursing students entering their first nursing course.

The student and family/significant other orientation program for this study was designed with the needs of both traditional and non-traditional students in mind. Non-traditional students are often defined as individuals older than 24 years of age who are most likely to have a job and family responsibilities. ${ }^{[4]}$ Many students would like to involve their families and significant others in their education for the purpose of sharing plans and visions of their positive completion of the nursing program. ${ }^{[5]}$ The inclusion of family and significant others was intended to allow for the building of a support system. ${ }^{6]}$ Family duties, work conflicts, child care conflicts, extracurricular activities and prior life experiences are all necessary to consider when designing an effective orientation program. ${ }^{[4]}$ We believe that students will benefit when family members and significant others have knowledge of the nursing program process and can provide appropriate support as the student.

\subsection{Purpose of the study}

The purpose of this study was to determine if an orientation program reduced the perceived anxiety of students who have been admitted to their first nursing course, and of their families and significant others. The goal of the orientation program was to facilitate students to begin the socialization process into the nursing major and to help family and significant others to understand their role in assisting students to achieve success, by exposing families and significant others to the requirements of the nursing major. Reducing anxiety for all persons who have an influence on a student's success can increase a student's ability to socialize and be successful..$^{[1,5]}$

\subsection{Literature review}

Orientation programs are key to achieving student success. They decrease anxiety and facilitate student persistence in order to increase their rates of retention and success of completing the nursing program. ${ }^{[5,7-10]}$ Students entering a new area of study tend to isolate and attempt to learn as individuals rather than acclimate and take part in group activities. ${ }^{[11,12]}$ Traditional and non-traditional students present with different needs when starting a new educational forum. Both come with unique conflicts with work, extracurricular activities, family responsibilities, and goals, as well as with prior college and life experiences. ${ }^{[4]}$ Students need to understand and become socialized to the institutional culture. ${ }^{[12,13]}$ They benefit when family and significant others are involved

Published by Sciedu Press in the socialization process, developing strategies that support students with new academic encounters. ${ }^{[13,14]}$ Having this type of support promotes student success. ${ }^{[12,13]}$ Many students begin new academic challenges, such as nursing programs, ill prepared for the cognitive and social demands placed upon them. ${ }^{[15]}$ This can lead to feelings of uncertainty and of not belonging to the program or college. ${ }^{[16]}$ Orientation programs tend to increase a student's overall college involvement. ${ }^{[7]}$ An orientation program may help students to feel connected to the school and nurture a sense of importance. ${ }^{[5]}$

Increasing knowledge during orientation programs is directly related to increasing socialization skills in a variety of settings. ${ }^{[4,17]}$ Warning ${ }^{[18]}$ found that new nursing students often separate their lives as nursing students from the lives lived by students in other majors. It is thought that activities enjoyed by students in other majors are not feasible for them.

Orientation programs are typically the first opportunity many students have to begin developing the knowledge that is necessary to achieve success. ${ }^{[4]}$ It is vital that all orientation programs incorporate skills and resources to facilitate the academic process. ${ }^{[19]}$

Anxiety may increase the incidence of a negative perception students have in believing that they have made the right decision in order to maintain an optimistic point of view regarding academic pursuits. ${ }^{[20]}$ Altman et al. ${ }^{[12]}$ found that students held an optimistic attitude when an orientation program allowed for the association with faculty that facilitates teaching courses involving new students with upperclassmen perspectives and descriptions of the curriculum.

New students are more engaged if there is initial involvement with other students and upperclassmen, already in the program. ${ }^{[19,21]}$ Positive faculty and student relationships can be a very important aspect to a student's overall college experience. ${ }^{[22,23]}$ The process of incorporating upper level nursing students in the orientation process tends to bring students closer, improves communication, and enhances the new student's support system. ${ }^{[24]}$ Optimism is directly equated with decreased anxiety and a feeling of being where one should with academic undertakings. ${ }^{[25]}$ Nursing students who were not happy typically had higher anxiety levels. ${ }^{[26]}$ Orientation programs may increase overall student satisfaction by decreasing anxiety levels. ${ }^{[7]}$

Nursing students experience much more anxiety than students in other majors. ${ }^{[1,12]}$ High anxiety is directly associated with a lack of understanding and knowledge. This stress and anxiety is also related to the level of student success. ${ }^{[13]}$ Learning and knowledge are impaired in the presence of high 
anxiety. ${ }^{[27]}$ Faculty must engage students, family, and significant others so the stress levels of students decreases, ${ }^{[13]}$ allowing for greater socialization into the culture of a nursing program. ${ }^{[1,12]}$ If an individual has elevated anxiety their motivation to learn may decrease and thus affect overall performance. ${ }^{[28]}$ Family and significant other involvement in orientation has been shown to have a positive effect and increase motivation. ${ }^{[27,29]}$

In order to validate orientation programs it is important to evaluate programs to determine if they are continuing to meet the needs of students, families, and significant others. Finding the most effective method of evaluation is an important component of constructing an orientation program. ${ }^{[30]}$ Measuring the anxiety levels of students, families, and significant others before and after an orientation program allows faculty to determine if the program decreased anxiety levels. ${ }^{[7,30]}$

Spielberger's State-Trait Anxiety Inventory (STAI) has been successfully used to measure anxiety in nursing students, as well as undergraduate and graduate students in a variety of programs. ${ }^{[7,14,31]}$ Charlesworth et al. ${ }^{[31]}$ define state anxiety as a direct perception of trepidation connected with an autonomic nervous system response and trait anxiety as the degree to which a person expresses anxiety in relationship to the type and amount of stress they are exposed to. Each type of anxiety is measured through the questions on the STAI by either positive or negative emotion identifiers.

Nursing students were administered the STAI before and after a stress management program. The results indicated that the instrument was valid and reliable, and that the stress management program was effective in reducing anxiety related to test taking in nursing students. ${ }^{[31]}$ The STAI was used again by Hullinger and Hogan ${ }^{[7]}$ to measure if an orientation program decreased the anxiety level of incoming graduate students. This was accomplished by first determining the level of anxiety that existed by administering the instrument, then exposing the graduate students to an online orientation program and re-administering the STAI after the orientation program was completed. The STAI was determined to be easy to administer, taking only 15 minutes to complete, as well as have strong reliability and validity. Reliability is reported to have an internal consistency score of 0.83 to $0.92 .^{[32]}$ The validity and reliability of this measurement tool has been utilized extensively in "STAI Manual for State-Trait Anxiety Inventory."[32]

\section{Methodology}

The purpose of this study was to determine if an orientation program reduced the perceived anxiety of students who have been admitted to the professional phase of the nursing major, as well as that of their family and significant others. The professional phase is the beginning of the student's enrollment in nursing courses and occurs in their sophomore year. The goal of the orientation program was to facilitate students to begin the socialization process into the nursing major and to help family and significant others to understand their role in assisting the student to achieve success by exposing family and significant others to the requirements of the major.

\subsection{Research question}

The research question was: What is the effect of an orientation program, held at the start of the professional phase, on the perceived anxiety levels students, family, and significant others have regarding success in the nursing program? The study hypothesized that conducting an orientation program would reduce perceived anxiety of students, family, and significant others regarding the ability to meet program requirements.

\subsection{Data collection instrument}

Data were collected using the STAI. All students, family, and significant others who decided to participate in the orientation program were given the STAI as part of the orientation program process. The exception was significant others under the age of 10. Excluding anyone under age of 10 was decided secondary to most 10 -year olds having an inability to decode material, and read with accuracy. ${ }^{[33]}$

\subsection{Program and demographics}

The orientation program was offered twice, once on a weekday evening and a second time on a Saturday morning. All students registered for their first nursing course were required to attend one of the sessions. This consisted of sophomore students in their second semester immediately prior to their first nursing course. Students were encouraged to bring family members and significant others to the orientation. Of the 36 students who participated in the orientation program, 27 consented to participate in the study. There were 33 family members and significant others who took part in the orientation program, out of which 25 participated in the study. Family members and significant others were considered an important component of this study since their involvement can enhance success for students. ${ }^{[34]}$ The demographics of the student population for this class consists of $13 \mathrm{Cau}-$ casians, 8 Hispanics/Latinos, 7 Pacific Islanders, 5 Blacks, and 5 Asians. The age range was 21-52 years and there were 28 females and 8 males.

The orientation forum was a presentation followed by an opportunity for questions and answers. The content of the orientation presentation covered an outline of the policies and procedures of the department of nursing, support services 
and other programs available to the students, requirements for progression in the program, and expectations for participation in clinical rotations. In addition, strategies for success were discussed. For example, ways that the student's family members and significant others could provide support and decrease anxiety for the students were brainstormed with the group. It has been shown that when families and significant others share insights regarding stress and anxiety, they are in a better position to help students with the challenges academia presents. ${ }^{[13]}$ The major focus of the program was anxiety and stress reduction techniques. Senior nursing students in their last semester of their senior year participated in the discussion and provided specific examples of how they and their peers achieved success. The senior students, as well as faculty, were able to answer the many questions asked of the program participants.

After obtaining IRB approval from the New York Institute of Technology's office of sponsored research, the STAI was administered to measure changes in stress levels before and after the orientation program. The STAI is in the public domain and does not require permission for its use. The STAI contains 10 variables that marked positive emotional or affective responses and 10 variables that marked negative emotional or affective responses. Participants rate their responses in terms of $1=$ not at all, $2=$ somewhat, $3=$ moderately so, and $4=$ very much so. $T$-tests were conducted to measure differences in scores achieved in pre- and postexposure to the intervention. The pre- and post-test method of collecting data is recommended for an orientation program experience. ${ }^{[30]}$ Data were collected anonymously.

Confidentiality was maintained by storing data collected in a locked file cabinet in the office of the primary investigator. Data were collected anonymously using graduate school non nursing volunteers from a different department within the School of Health Professions. No names or identifying numbers were on the data collection forms.

\section{RESULTS}

\subsection{Positive emotions}

Participants scored noticeably higher after exposure to the intervention with positive emotions such as, calmness, satisfaction, confidence, relaxation, contentment, and pleasure. The other measures of positive emotions, comfortable, steady, secure and at ease, either declined slightly or remained unchanged. All increases in test scores for positive emotions were statistically significant with the exception of feelings of security and comfort. When the ten questions were analyzed together to represent a cumulative score, outcomes estimated a pre-intervention score of $(\mathrm{M}=24.27, \mathrm{SD}=7.53)$ and postintervention score of $(\mathrm{M}=31.42, \mathrm{SD}=7.68)$. The six point increase $(\mathrm{M}=6.15, \mathrm{SD}=1.64)$ was statistically significant $(t$ $=27.10, p=.000)$. Results suggest the intervention was successful with enhancing positive feelings among participants (see Table 1).

Table 1. Average pre and post exposure scores (positive emotions): $t$-test $(\mathrm{N}=52)$

\begin{tabular}{llllll}
\hline Score & Mean & SD & $\boldsymbol{t}$ & $\boldsymbol{d f}$ & $\boldsymbol{p}$ \\
\hline Pre-Test & 24.27 & 7.53 & 27.10 & 51 & $.000^{* *}$ \\
Post-Test & 31.42 & 7.68 & & & \\
Paired Difference & 6.15 & 1.64 & & & \\
\hline
\end{tabular}

$* * p \leq .01$

\subsection{Negative emotions}

Negative affective responses were measured before and after the intervention. Students scored significantly lower on negative emotions such as, feeling strained, upset, nervous, jittery, worried and confused after the intervention. When the ten questions were analyzed together as a cumulative score, it was found that the average pre-intervention score $(\mathrm{M}=26.48$, $\mathrm{SD}=6.72)$ declined dramatically to $(\mathrm{M}=15.51, \mathrm{SD}=7.15)$. This decrease of over eleven points $(\mathrm{M}=-11.27, \mathrm{SD}=4.34)$ was highly statistically significant $(t=-18.72, p=.000)$ and suggests the intervention was successful with substantially decreasing negative emotions (see Table 2).

Table 2. Average pre and post exposure scores (negative emotions): $t$-test $(\mathrm{N}=52)$

\begin{tabular}{llllll}
\hline Score & Mean & SD & $\boldsymbol{t}$ & $\boldsymbol{d f}$ & $\boldsymbol{p}$ \\
\hline Pre-Test & 26.48 & 6.72 & -18.72 & 51 & $.000^{* *}$ \\
Post-Test & 15.51 & 7.15 & & & \\
Paired Difference & -11.27 & 4.34 & & & \\
\hline ** $p \leq 01$
\end{tabular}

\subsection{Significance of results}

Post-hoc power analyses were performed using $\mathrm{G}^{*}$ Power 3.1.9.2. Post-hoc power analyses assume the results from the sample in the study reflect the population perfectly, and then calculate the probability that a sample of the same size from that population would result in statistical significance. For the positive emotions score, the effect size of Cohen's $d=$ 3.75 (considered quite large by general standards, which consider anything larger than a magnitude of 0.8 to be "large"). The observed power for a sample of size 52 and a significance level of 0.05 is 1.00 , which is the largest that power can be (this means there is virtually a $100 \%$ chance of finding a statistically significant result for a sample of this size). For the negative emotions score, the effect size of Cohen's d = -2.60 (also quite large); the observed power for a sample of size 52 and a significance level of .05 is again 1.00. 


\section{Discussion}

When planning the orientation program it was the intention of the faculty who teach the introductory course to create a student body who were more prepared to begin nursing courses and have the resources to succeed. It was also the object to facilitate helping the students create a support system that fosters success both with peers and significant others. Reducing student and significant other stress regarding the demands of the major was viewed as one way to assist students to build a support system and have the ability to recognize when to use that support system to foster success. The results indicated that there was an overall decrease in anxiety after participating in the orientation program. In addition to the significant increase in positive emotions and decrease in negative emotions, students and significant others expressed satisfaction through both written and verbal comments.

Students articulated satisfaction with the input the upperclassmen added to the information provided. One example is how the upperclassmen spoke about the need to organize time, providing examples of how they manage their time. This correlated directly with the increase in positive emotions such as feeling calm, confident, relaxed, and content. The upperclassmen discussed how their families presently assist them with having more time to study, for example taking care of daily chores and assisting with childcare. Family members and significant others, as well as the incoming students asked many questions of the upperclassmen regarding how significant others can get involved in making nursing school a more pleasant and successful experience. This correlates with the decrease in negative emotions such as feeling strained, upset, nervous, and worried.

Information provided on how the program is set up with regard to clinical expectations and test preparation could be seen as directly linked to the decreasing of the negative emotions of nervousness, jittery feelings, worries and confusion. The increase in positive emotions and decrease in negative emotions supported the achievement of the goal of the orientation program, to facilitate students to begin the socialization process into the nursing major and to help family and significant others to understand their roles in assisting the student to achieve success by exposing family and significant others to the requirements of the nursing major.

The study provided the researchers with valuable information not indicated in the data analysis. Keeping current, through continuous programs and surveys, with student needs could enhance student retention and success in the program. Since the results were positive with decreasing anxiety, it is felt by the researchers that the orientation program provided important information, and therefore attendance should be required for all future students.

Although the study provided valuable information about the need to provide such a program to increase student success, there were some limitations. Including more detailed demographics might have provided greater insight into the type of students surveyed so the researchers could gain a better understanding of student needs. For example, knowing more demographics, such as related healthcare roles held, could allow the organizers of the program to adjust the information provided to better suit the population of participants. More information might be provided if the sample size was larger. The validity of the study would be stronger with a larger sample size. An additional limitation was that the significant others and the students were not separated in the data analysis. The possibility for the need for two separate orientation programs could have been determined if these data were separated.

Future studies should take in account the limitations stated. Knowing key demographics such as cultural needs might further increase positive emotions and decrease negative emotions by including necessary information that is specific to the cultural needs of the student population. Increasing the study to track emotions during and after the first year might strengthen the validity of the results if answers continue to support an increase in positive emotions and decrease in negative emotions.

\section{Conclusion}

Based on the information gathered from the STAI, the goal of the orientation program was considered to be met. Orientation programs may fulfill many important functions such as disseminating important data, increasing program success, increasing socialization, and decreasing anxiety. The data collected from this study supported the purpose of decreasing student and significant other anxiety. Reducing anxiety increases an individual's well-being. When individuals are anxious about their own health, their skills tend to suffer. This may be dangerous leading to decreased performance. The results of this study adds credence to the belief that decreasing anxiety might increase student performance.

\section{CONFlicts of InTEREST Disclosure}

The authors declare that there is no conflict of interest. 


\section{REFERENCES}

[1] Driscoll R, Evans G, Ramsey G, et al. High Test Anxiety among Nursing Students. Institute on Education Sciences [Internet]. 2009; Available from: http://eric.ed.gov/?id=ED506526

[2] Viverais-Dresler G, Rukholm E, Koren I. Hassles, uplifts, and anxiety reported by Post-RN students in a $\mathrm{BScN}$ programme. Nurse Educ. Today [Internet]. 1991; 11: 415-423. Available from: http s://www.ncbi.nlm.nih.gov/pubmed/1775119 https://doi. org/10.1016/0260-6917(91)90003-S

[3] Mohamadkhani Shali E, Alipor A, Hasanzadeh Pashang S. Effect of cognitive therapy training in groups on health anxiety among nursing students. Journal of Jahrom University of Medical Sciences [Internet]. 2013; 11: 53. Available from: http://core.ac.uk/download/ pdf/27038115.pdf

[4] Knox MJ, Henderson BD. Nontraditional is the new traditional: Understanding today's college student. In: Ward-Roof JA, Lee Upcraft M, Hatch C, et al., editors. Designing Successful Transitions: A Guide for Orienting Students to College. 3rd ed. Columbia, SC: University of South Carolina National Resource Center for The First Year Experience \& Students in Transition; 2010.

[5] Cubarrubia AP, Schoen JC. Creating a developmental framework for new student orientation to address the needs of diverse populations. In: Ward-Roof JA, Lee Upcraft M, Hatch C, et al., editors. Designing Successful Transitions: A Guide for Orienting Students to College. Columbia, SC: University of South Carolina National Resource Center for The First Year Experience \& Students in Transition; 2010.

[6] Mullendore RH, Banahan LA. Designing Orientation Programs. In: Lee Upcraft M, Gardner JN, Barefoot BO, editors. Challenging and Supporting the First-Year Student: A Handbook for Improving the First Year of College. San Francisco, CA: Jossey-Bass; 2004. PMid:15153434

[7] Hullinger M, Hogan RL. Student anxiety: Effects of a new graduate student orientation program. AIJ [Internet]. 2014; 4: 27-34. Available from: https://submissions.scholasticahq. com/supporti ng_files/248858/attachment_versions/249098

[8] Mack CE. A brief overview of the orientation, transitions, and retention field. In: Ward-Roof JA, Lee Upcraft M, Hatch C, et al., editors. Designing Successful Transitions: A Guide for Orienting Students to College. 3rd ed. Columbia, SC: University of South Carolina National Resource Center for The First Year Experience \& Students in Transition; 2010.

[9] Mangold WD, Bean LG, Adams DJ, et al. Who goes who stays: An assessment of the effect of a freshman mentoring and unit registration program on college persistence. J. Coll. Stud. Ret. 2002; 4: 95-122. https://doi.org/10.2190/CVET-TMDM-CTE4-AFE3

[10] Kotter JP. A Sense of Urgency. Boston, MA: Harvard Business Press; 2008.

[11] Cooke R, Bewick BM, Barkham M, et al. Measuring, monitoring and managing the psychological well-being of first year university students. Br. J. Guid. Counc. [Internet]. 2006; 34: 505-517. http://dx.doi.org/10.1080/03069880600942624

[12] Altman MI, Musselman M, Curry L. Success begins in nursing freshman orientation course. Nurse Educ. [Internet]. 2010; 35: 6-7. http://dx.doi.org/10.1097/NNE.0b013e3181c41f7b

[13] Hoover SC. Designing orientation and transition programs for transfer students. In: Ward-Roof JA, Lee Upcraft M, Hatch C, et al., editors. Designing Successful Transitions: A Guide for Orienting Students to College. 3rd ed. Columbia, SC: University of South Carolina National Resource Center for The First Year Experience \& Students in Transition; 2010.

Published by Sciedu Press
[14] Patton TJ, Goldenberg D. Hardiness and anxiety as predictors of academic success in first-year, full-time and part-time RN students. J. Contin. Educ. Nurs. [Internet]. 1999; 30: 158-167. Available from: https://www.ncbi.nlm.nih.gov/pubmed/104744 18 PMid: 10474418

[15] Cubarrubia AP, Schoen JC. Creating a developmental framework for new student orientation to address the needs of diverse populations. In: Ward-Roof JA, Lee Upcraft M, Hatch C, et al., editors. Designing Successful Transitions: A Guide for Orienting Students to College. Columbia, SC: University of South Carolina National Resource Center for The First Year Experience \& Students in Transition; 2010.

[16] Alnawas I. Prospective student orientation in higher education: Development of the construct. Journal of Customer Behaviour [Internet]. 2014; 13: 135-163. Available from: http://www.ingentaconnect.com/content /westburn/jcb/2014/00000013/00000002/art00005 https://doi.org/10.1362/147539214X14024779483636

[17] Acevedo JM, Yancey GB. Assessing new employee orientation programs. Journal of Workplace Learning [Internet]. 2011; 23: 349-354. http://dx.doi.org/10.1108/13665621111141939

[18] Warning LM. Are you positive? The influence of life orientation on the anxiety levels of nursing students. Holist. Nurs. Pract. [Internet] 2011; 25: 254-257. Available from: http://dx.doi.org/10.10 97/HNP. Ob013e31822a02c7

[19] Cuevas CJ, Timmerman C. Community college orientation and transition progams. In: Ward-Roof JA, Lee Upcraft M, Hatch C, et al., editors. Designing Successful Transitions: A Guide for Orienting Students to College. Columbia, SC: University of South Carolina National Resource Center for The First Year Experience \& Students in Transition; 2010.

[20] Craft J, Hudson P, Plenderleith M, et al. Commencing nursing students' perceptions and anxiety of bioscience. Nurse Educ. Today [Internet]. 2013; 33: 1399-1405. http://dx.doi.org/10.1016 /j.nedt.2012.10.020

[21] Pascarella ET, Terenzini PT. How College Affects Students: Findings and Insights from Twenty Years of Research. San Francisco, CA: Jossey-Bass; 1991.

[22] Cotten SR, Wilson B. Student-faculty Interactions: Dynamics and Determinants. High Educ [Internet]. 2006 [cited 2016 Dec 28]; 51: 487-519. Available from: http://link.springer.com/articl e/10.1007/s10734-004-1705-4

[23] Kramer GL. Student academic services: An integrated approach. San Francisco, CA: Jossey-Bass; 2003.

[24] Skipper TL, Latino JA, Moody-Rideout B, et al. Extensions of traditional orientation programs. In: Ward-Roof JA, Lee Upcraft M, Hatch C, et al., editors. Designing Successful Transitions: A Guide for Orienting Students to College. 3rd ed. Columbia, SC: University of South Carolina National Resource Center for The First Year Experience \& Students in Transition; 2010.

[25] Wigley SC. Assessment of Morale in Further Education Students Studying for A-level Examinations. Journal of Further and Higher Education [Internet]. 2004; 28: 423-434. http://dx.doi.org/10. 1080/0309877042000298885

[26] Biggers T, Zimmerman RS, Alpert G. Nursing, nursing education, and anxiety. J. Nurs. Educ. [Internet]. 1988; 27: 411-417. Available from: https://www.ncbi.nlm.nih.gov/pubmed/285271 4 PMid:2852714

[27] Worrall K. Orientation to student placements: needs and benefits Paediatr. Nurs. [Internet]. 2007; 19: 31-33. http: //dx. doi .org/1 $0.7748 /$ paed2007.02.19.1.31.c4443 
[28] Nicklin PJ, Kenworthy N. Teaching and Assessing in Nursing Practice: An Experiential Approach. 3rd ed. Kent, UK: Baillière-Tindall; 2000.

[29] Kim JI, Chung H. The role of family orientation in predicting Korean boys' and girls' achievement motivation to learn mathematics. Learn. Individ. Differ. [Internet]. 2012; 22: 133-138. Available from: http://www.sciencedirect.com/science/arti cle/pii/S1041608011001592

[30] Schwartz R, Wiese D. Assessment and evaluation in orientation. In: Ward-Roof JA, Lee Upcraft M, Hatch C, et al., editors. Designing Successful Transitions: A Guide for Orienting Students to College. 3rd ed. Columbia, SC: University of South Carolina National Resource Center for The First Year Experience \& Students in Transition; 2010.

[31] Charlesworth EA, Murphy S, Beutler LE. Stress management skill for nursing students. J. Clin. Psychol. [Internet]. 1981; 37: 284-290.
Available from: https://www.ncbi.nlm.nih.gov/pubmed/61 12243

[32] Spielberger CD, Gorsuch RL, Lunshene RE. The State-Trait Anxiety Inventory Manual. Palo Alto, CA: Consulting Psychologists Press; 1970. https://doi.org/10.1002/1097-4679(198104 ) $37: 2<284:$ : AID- JCLP2270370210>3 . 0. CO ; 2-8

[33] Klauda SL, Guthrie JT. Relationships of three components of reading fluency to reading comprehension. J. Educ. Psychol. [Internet]. 2008 [cited 2016 Dec 28]; 100: 310-321. http://dx.doi .org/10.10 37/0022-0663.100.2.310

[34] Cutright M. From helicopter parent to valued partner: shaping the parental relationship for student success. In: Barefoot BO, editor. The First Year and Beyond: Rethinking the Challenge of Collegiate Transition: New Directions for Higher Education, Number 144. San Francisco, CA: Jossey-Bass; 2008. https ://doi.org/10.1002/ he. 324 